\title{
REVIEW
}

\section{Irradiation of Foods: A Better Alternative in Controlling Economic Losses}

\section{INABO, H I}

\author{
Department of Microbiology, Faculty of Science, Ahmadu Bello University, Samaru-Zaria, Nigeria.
}

\begin{abstract}
Food irradiation as a better alternative to other food processing methods is discussed. Irradiation is a promising new food safety technology that can eliminate disease-causing microorganisms such as E.coli 0157:H7, Camplyobacter and Salmonellae from foods; delay maturation of fruits and inhibit sprouting of bulbs and onions. The yearly and cyclic scarcity of fruits and vegetables during their non-productive period is a known phenomenon in most developing countries. Post-harvest losses are due to microorganisms, which destroy these foods. The process, consumer acceptance, nutritional and microbiological safety are highlighted in this paper. @JASEM
\end{abstract}

Food irradiation is the process of preserving foods by exposing them to ionizing or high energy electrons and $\mathrm{X}$ rays. Electron beams and $\mathrm{x}$-rays radiators are operated by electricity and do not require the use of radioactive isotopes. These break the chemical bonds in the molecules that are essential for cell growth and integrity. The aim of this is to improve product safety and shelf life. As a result, the microorganisms die and can no longer cause illness or spoilage. Food irradiation is a tool for improving food safety by killing pathogenic organisms. It also serves as a complimentary process to good manufacturing practices. The process of food irradiation is called "cold pasteurisation" because it kills harmful bacteria without the use of heat. Gamma rays or electron beams can be used to irradiate foods. Foods exposed to gamma rays emanating from a radiating source such as Cobalt-60 may be processed in the food plant, packaged with oxygenpermeable film and transported to an irradiation facility. During irradiation, only the gamma rays come in contact with the food, breaking the bonds with the DNA molecules and causing defects in the genetic instructions. The effectiveness of the process depends on the organism's sensitivity to irradiation, on the state of the food before irradiation (whether fresh or frozen); and on the rate at which it can repair damage DNA. (USDA, 2002). Irradiated foods are not radioactive since the rays do not remain in the food. They have the same effect of destruction of microorganisms and prevention of sprouting in vegetables (particularly onions and potatoes), delay of maturation in fruits and vegetables (Lushinger, 1997). Irradiation has minimal effects on flavour, texture and aroma of raw and pre-cooked meat products (Lutter, 1999). The irradiation facility consists of a room with concrete walls that have the radiation source (Co-60 or Cs-137) in an industrial layout. A conveyor system moves the product into the irradiation room automatically and then removes it. If personnel must enter the room, the irradiation source must be lowered to the bottom of a pool. Here, the water absorbs the radiation energy. The gamma radiation source consists of Cobalt-60 rods in stainless steel tubes. These tubes are raised into concrete irradiation chamber to treat the food. Gamma rays have short wavelengths and high frequencies and hence penetrate the food so rapidly that little or no heat is produced. Hence, the process is called cold pasteurization (Roberts, 1998). The irradiated product must be handled carefully to prevent re-contamination. The amount of radiation that the food product absorbs is measured by a dosimeter in kilograys. There are 4 basic irradiator designs suitable for disinfection of fruits and vegetables. They are: Tote box concept, Carrier concept, Pallet carrier concept and Pallet conveyer concept. In the tote box concept, the product is packed in metal or fiberglass boxes called totes. A tote has a volume of $0.75 \mathrm{~m}^{3}$. The carrier concept uses tall aluminum carriers which are suspended; the carrier pallet uses pallet irradiators with overlapping sources while the pallet conveyor system combines the efficiency of the pallet radiator with the design of the tote box irradiator.

The safety of irradiated foods has been assessed by many scientific tests using numerous animal feeding tests such as cytogenetic analysis, host-mediated assays, micro-nucleus and multi-generation feeding tests. Most opponents of food irradiation alleged that polyploidy brings about chromosomal abnormality which is traceable to consumption of irradiated wheat. Scientific studies have shown that no chromosomal aberrations occur in animals and even human volunteers (Diehl, 1995). A wide range of problems arose in animals that ate irradiated foods as claimed by opponents of food irradiation. These problems include premature death, reproductive dysfunction, liver damage and cancer. At irradiation levels approved for use in foods, vitamin levels are slightly reduced but this is not enough to result in vitamin deficiency. Some flavour compounds may be altered. Compounds that were not originally present may be formed and this requires strict control of radiation levels. These compounds include the formation of 2-dodecylcylodutanone (2-DCB) and 2alkylcyclobutanones in foods containing fats (Delincee and Pool-Zobel, 1998). A number of factors determine the changes in nutritional value of the irradiated foods. These include the type of food, the radiation doses to which the food has exposed, packaging and processing condition. The nutritional losses are less generally, if oxygen is excluded from the packages to be irradiated at doses up to $1 \mathrm{kgGray}$. The irradiation process is not suitable for certain products. Off-odours and taste are common to foods high in fat content. This is because of acceleration of rancidity. Foods with high protein content also have flavour changes and odors. Irradiating the food in the frozen state and reducing 
the dosage used for irradiation can reduce this. Carbohydrates, fats and proteins are not reduced significantly by irradiation though vitamin losses are quite large (Brynjolfsson, 1985).

Benefits of food irradiation: Irradiation prolongs the shelf life of foods particularly fruits and vegetables by reducing spoilage bacteria. All organisms present in the food are destroyed to secure long term preservation. Meats, seafood, cereal grains, fruits and vegetables are preserved this way. Foods are available in and out of season. Inhibition of sprouting, senescence and maturation of fruits and vegetables are benefits of irradiation. Food irradiation has been used to control pests in grains and has been found to be better than fumigation. It maintains the sensory quality of foods, as knowledge of radiation chemistry has guided the development of means to prevent undesired sensory changes. For example, protein foods are irradiated in the frozen state to avoid off-flavour. Informed consumers will buy irradiated foods for the reasons such as safety from food poisoning bacteria, increased shelf life and superior product quality. For example, Strawberries treated with $1 \mathrm{~kg}$ of irradiation were mould-free for 25 days in the refrigerator while they will normally mold after 5 days when refrigerated. (Kilcast, 1994). Consumers support the labeling of irradiated foods with the international logo (Radura) and the words "treated with irradiation". The increase in price for irradiated food is insignificant considering the benefits the consumers get in terms of convenience, improved hygiene of the food, quantity and availability (Frenzen et al., 2000). A Joint Committee of the FAO, WHO and IAEA claimed that vitamin losses in foods treated with irradiation doses of $1 \mathrm{kGy}$ or less are minimal and compatible with vitamin losses in heat treated foods. Low-dose irradiation does not cause a significant decrease in the nutritional quality of foods. A misconception of irradiated foods is that unknown byproducts may be produced in the food during the radiation process and that the safety of these products is unknown, but the by-products produced in foods treated with radiation are naturally present in foods and are also formed by heat processing. The FDA Bureau of foods Irradiated Food Committee (BFIFC) found that 90 percent of all these compounds are similar to those foods treated by other preservation methods such as freezing, drying or heating(USDA,2002).

Irradiated Vegetables: Most of the irradiation research has been centered on vegetables particularly onions, garlic, mushrooms, potatoes, tomatoes. In tomatoes the aim is to suppress the decay mould Alternaria while in potatoes, garlic, and onions, sprouting inhibition is sought. In mushrooms, irradiation is expected to inhibit the opening of caps (Julius, 1999). Most of the fruits and vegetables are lost to post-harvest microbial destruction. Irradiation provides a better alternative to other food processing technologies. Insect control, increased shelf life, inhibited sprouting are some of the advantages of using irradiation to preserve food.

\section{REFERENCES}

Brynjolfsson, A(1989).Future radiation sources and identification of irradiated foods. Food Technol. 43(7):84-89, 97.

Delincee,H and Pool-Zobel, B L(1998). Genotoxic properties of 2-dodecylcloutanone, a compound formed on irradiation of food containing fat. Radiation Physics and Chemistry.52:39-42.

Diehill, JF (1992). Food irradiation: Is it an alternative to chemical preservatives? Food Additives and contaminants. 9: 409-416.

Diehill,JF(1995).Safety of irradiated foods. $2^{\text {nd }}$ edition Marcel Dekker Inc.New York.

Frenzen, PD; Majchrowisc, A; Buzby, JC; In, B. (2000).Consumer acceptance of irradiated meat and poultry products. Agriculture Information Bulletin. No.757

Kilcast, D (1994). Effect of irradiation on vitamins. Food chemistry.49:157-164.

Luchsinger, SE; Kropf, DH; Chambers, E; Zepeda,CMG;Hunt,MC;Stroda,SL;

Hollingsworth, ME ;Marsden, JJ; Kastner, CL(1997). Sensory analysis of irradiated gound beef patties and whole muscle beef. Journal of Sensory Studies. 12(2):105-126.

Lutter,R (1999). Food irradiation. The neglected solution to food-borne illness, Science.286:2275-2276.

Roberts,T (1998).Cold pasteurization of foods by irradiation. Virginia Cooperative Extension.pp1-12

USDA (2002).Gateway to government food safety information .Irradiation. Retrieved November, 2002 from http:www.foodsafety.gov/-fsg/irradiat.html. 